\title{
Toxicity Evaluation of Dextran Coated Ferrite Nanomaterials After Acute Oral Exposure to Wistar Rats
}

\author{
Syama S1 ${ }^{1}$ Reshma SC ${ }^{1}$, Leji B ${ }^{1}$, Anju M${ }^{1}$, Sreekanth PJ², Varma HK² and Mohanan PV ${ }^{\text {* }}$ \\ ${ }^{1}$ Toxicology Division, Sree Chitra Tirunal Institute for Medical Sciences and Technology, Kerala, India \\ ${ }^{2}$ Bioceramic Laboratory, Sree Chitra Tirunal Institute for Medical Sciences and Technology, Kerala, India
}

\begin{abstract}
Dextran Coated Ferrite Nanomaterials (DFNM) of size $<25 \mathrm{~nm}$ was synthesized, characterized and the acute oral toxicity along with antioxidant enzymes activities were evaluated in Wistar rats. The healthy adult rats were orally administered with 300 and $2000 \mathrm{mg} / \mathrm{kg}$ body weight of DFNM using a gastric needle and observed for 14 days. None of the animals showed any adverse effects/toxicity at the end of observation period. After two weeks of administration, blood was collected and subjected to haematological and biochemical analysis. Animals were sacrificed and gross necropsy was done on all animals. Liver was dissected; homogenized (10\% homogenate) and rate of formation of lipid peroxides were evaluated. In addition, the concentration of reduced glutathione and the activity of vital antioxidant enzymes like glutathione reductase, glutathione peroxidase and superoxide dismutase was determined. The result of the study indicates that even at $2000 \mathrm{mg} / \mathrm{kg}$ body weight, DFNM was non-toxic. It was also observed that there was a slight fluctuation in the level of antioxidant enzymes activity, lipid peroxidation, haematological and biochemical parameters but it was not significant. Hence, it can be concluded that the in-house synthesized DFNM was non-toxic and shows no lethal effects when orally exposed to rats.
\end{abstract}

Keywords: Dextran coated ferrite nanomaterial; Oral toxicity; Oxidative stress; Antioxidant enzymes

\section{Introduction}

In the present age, the use of nanomaterials is expanding tremendously but the safety of these nanomaterials to human health is poorly known. Nanomaterials are engineered structures with at least one dimension of 100 nanometers or less. Apart from commercial purpose, nanomaterials have gained much application in healthcare systems, particularly in imaging and targeted drug delivery systems. Magnetic nanoparticles are particularly appealing and are widely used in biomedical applications as contrast agents in magnetic resonance imaging (MRI) [1], in tissue repairing [2], detoxification of biological fluids, hyperthermia [3], drug delivery [4], cell separation [5] and drug targeting [6] etc.

Ferrite particles coated with biocompatible phases like hydroxyapatite is employed for hyperthermia treatment of cancer [7]. As bare metal and metal oxide nanoparticles are toxic to biological systems, coating with biocompatible phases are often done to increase the biomimmetic nature of the particles suiting for various biomedical applications. Dextran $\left(\mathrm{C}_{6} \mathrm{H}_{10} \mathrm{O}_{5}\right)$, a branched polysaccharide, obtained by microbial synthesis is used to coat iron nanoparticles. Dextran being nontoxic, biodegradable and hydrophilic may facilitate the intra cellular uptake of dextran coated magnetic iron particles [8].

Toxicity of the nanomaterials may be due to the release of its chemical entities or its physical presence in tissues, which may results in the local tissue response, systemic toxicological response, allergic response, carcinogenic or mutagenic response and so on. Toxicity may also arise because of the components get accumulated and become concentrated. Acute toxicity involves any harmful effects produced in an organism through a single or multiple exposures within a period of $24 \mathrm{~h}$, resulting in severe biological harm or death. The sole purpose of acute toxicity is to detect and provide a degree of quantitation of the biological activity and lethal effects of a substance following the oral, dermal or inhalation exposure. From this assay, it is possible to determine whether a substance is very toxic or toxic or less toxic. The results may split into five categories (Category 1-5) of severity. Category
1 requires the least amount of exposure to be lethal while Category 5 requires the most exposure to be lethal [9].

The molecular mechanisms of toxicity of nanoparticles are still underway. Experimental evidence has shown that metal and metal oxide nanoparticles, through the generation of reactive oxygen species (ROS) induce oxidative stress mediated DNA damage and apoptosis [10]. Due to the high reactivity of ROS, most cellular components are likely to be the targets of oxidative damage resulting in lipid peroxidation, protein oxidation, GSH depletion, DNA single strand breaks. All of these events ultimately lead to cellular dysfunction and injury [11]. Antioxidant defense system that plays a critical role in maintaining cellular homogeneity includes both low-molecular-weight free radical scavengers like tripeptide glutathione, as well as antioxidant enzymes, such as superoxide dismutase, Glutathione reductase and glutathione peroxidase [8]. For this reason, antioxidant enzymes are considered as vital markers for oxidative stress induced in the body.

Here, dextran coated ferrite nanomaterials intended to be used for targeted drug delivery applications were synthesized in-house and was characterized before proceeding to the toxicity evaluation. The present study was designed to provide information on the acute oral toxicity of dextran coated ferrite nanoparticles and its effects on various parameters like haematological, biochemical, antioxidant enzymes, reduced glutathione and lipid peroxidation.

*Corresponding author: Mohanan PV, Toxicology Division, Biomedical Technology Wing, Sree Chitra Tirunal Institute for Medical Sciences and Technology, Thiruvananthapuram 695 012, Kerala, India, Tel: 91-471-2520266 Fax: 91-471-2341814; E-mail: mohanpv10@gmail.com/mohanpv@sctimst.ac.in

Received December 30, 2013; Accepted March 02, 2014; Published March 07 2014

Citation: Syama S, Reshma SC, Leji B, Anju M, Sreekanth PJ, et al. (2014) Toxicity Evaluation of Dextran Coated Ferrite Nanomaterials After Acute Oral Exposure to Wistar Rats. J Allergy Ther 5: 166. doi:10.4172/2155-6121.1000166

Copyright: ( 2014 Syama S, et al. This is an open-access article distributed under the terms of the Creative Commons Attribution License, which permits unrestricted use, distribution, and reproduction in any medium, provided the original author and source are credited. 


\section{Materials and Methods}

\section{Chemicals}

Dextran coated ferrite nanoparticles (SCTIMST, India), thiobarbituric acid (TBA), reduced glutathione (GSH), oxidized glutathione (GSSG), dithio-bis-2-nitrobenzoic acid [DTNB], RNase (Sigma, USA), disodium hydrogen phosphate $\left(\mathrm{Na}_{2} \mathrm{HPO}_{4}\right)$, sodium dihydrogen phosphate $\left(\mathrm{NaH}_{2} \mathrm{PO}_{4}\right)$, ethylene triamine tetra acetic acid (EDTA) (Merck, Germany), physiological saline (Parenteral Drugs Ltd., India). All the chemicals and reagents used were of analytical grade.

\section{Experimental animals}

Healthy Wistar rats weighing 200-250 g were maintained in a $12-\mathrm{h}$ light/dark cycle at a constant temperature of $22 \pm 3^{\circ} \mathrm{C}$ with free access to standard pellet diet and water. Animal experiments were carried out according to the guidelines of Institute Animal Ethics Committee regulations approved by Committee for the Purpose of Control and Supervision of Experiments on Animals.

Individual animals were identified with picric acid marks. In addition to this, each animal cage was identified by labels having details such as experiment number, name, animal number(s) and date of experiment. All the animals were acclimatized for a period of 5 days before initiation of experiments.

\section{Animal husbandry and welfare}

All animals were handled humanely, without making pain or distress and with due care for their welfare. The care and management of the animals will comply with the regulations of the Committee for the Purpose of Control and Supervision of Experimental Animals (CPCSEA), Govt. of India. All the animal experiments were carried out after prior approval from Institutional Animal Ethics Committee and in accordance with approved institutional protocol.

\section{Synthesis of dextran coated ferrite nanomaterials}

Dextran-coated ferrite nanomaterials (size $<25 \mathrm{~nm}$ ) were prepared using the co-precipitation method. Briefly, the stoichiometric mixtures of $\mathrm{FeCl}_{3}$ and $\mathrm{FeCl}_{2} .4 \mathrm{H}_{2} \mathrm{O}\left(\mathrm{Fe}^{3+} / \mathrm{Fe}^{2+}: 2: 1\right)$ were heated at $70^{\circ} \mathrm{C}$. Ferrite nanoparticles were precipitated by the addition of $3 \mathrm{M} \mathrm{NaOH}$ drop wise for $1 \mathrm{~h}$ followed by hot stirring for another $1 \mathrm{hr}$. The precipitate was then washed three times with deionized water to get uniformly dispersed spherical magnetite particles. The overall reaction was carried out in $\mathrm{N}_{2}$ atmosphere to prevent oxidation of magnetite to magnemite. Surface coating of ferrite nanoparticles with dextran was done by stirring ferrite nanomaterial in a solution of dextran of appropriate concentration for overnight $\left(\right.$ at $\left.37^{\circ} \mathrm{C}\right)$. The precipitate was then washed and lyophilized to obtain dextran coated nanomaterials (DFNM) [12].

\section{Characterization of DFNM}

The size of synthesized DFNM was studied by Transmission Electron Microscopy (TEM) analysis. For TEM analysis, the sample was prepared by ultrasonication of the synthesized DFNM and dispersion of DFNM as a thin coat on top of the copper grid.

\section{Acute toxicity}

Acute oral toxicity is to provide information on the possible health hazards likely to arise from the single or multiple exposures to a substance within a period of $24 \mathrm{~h}$. For oral administration, the DFNM was suspended in aqua guard water and was loaded in a syringe after thorough agitation. A single administration of this suspension was given to rats using a gastric needle. DFNM of $300 \mathrm{mg} / \mathrm{kg}$ body weight was orally given to 3 wistar rats. Another 3 more rats were administered with DFNM of $2000 \mathrm{mg} / \mathrm{kg}$ body weight. The experiment was repeated with each dose for confirmation. All these animals were observed for 14 days for the evidence of any adverse reactions/toxicity or death [13] following DFNM exposure.

\section{Haematological and Biochemical parameters}

At the end of the experimental period, blood was collected from the orbital sinus of the animals. For hematology analysis, blood was collected in tubes with EDTA. Hematological parameters such as hemoglobin concentration $(\mathrm{Hb})$, total erythrocyte count (RBC), white blood cell (WBC), hematocrit (HCT), total and differential leukocyte counts were evaluated using haematology counter.

For biochemical estimation, the serum was obtained by centrifugation of the whole blood at $3000 \mathrm{rpm}$. The biochemical parameters such as ALP, SGOT, SGPT, GGT, albumin, total protein, glucose, cholesterol, urea, creatinine, total bilirubin, phosphorous etc were estimated using ERBA XL 300 Biochemical Fully automated analyzer. All the diagnostic kits were purchased from Transasia Biomedical Ltd, Mumbai.

\section{Gross pathology}

Animals were sacrificed by cervical dislocation and gross necropsies were performed which include examination of the external surface of the body and internal organs. All major organs such as heart, liver, lungs, kidneys, spleen and adrenals were observed for any gross abnormalities.

\section{Preparation of liver homogenate}

For anti oxidant studies, $10 \%$ liver tissue homogenate (Phosphate buffer, $\mathrm{pH}$ 7.4) was prepared from the untreated and treated animals of both the concentrations ( 300 and $2000 \mathrm{mg} / \mathrm{kg}$ body weight). The homogenate was then centrifuged at $3500 \mathrm{rpm}$ for $10 \mathrm{~min}$ at $4^{\circ} \mathrm{C}$ in a refrigerated centrifuge. The resultant supernatants were maintained in an ice bath and are used as the sample for the estimation of total protein, lipid peroxidation, glutathione reductase, reduced glutathione, glutathione peroxidase and superoxide dismutase as per the standard protocols with slight modifications.

\section{Total protein}

Lowry's et al. [14] method was followed for the estimation of total proteins using bovine serum albumin as standard.

\section{Lipid Peroxidation (LPO)}

The extent of lipid peroxidation in the above prepared liver homogenate was determined as described by Ohkawa et al. [15]. This method is based on the increase in malondialdehyde formation in response to increased peroxides within the cell. The malondialdehyde (MDA) thus produced reacts with thiobarbituric acid reactive substances (TBARS) forming a complex. The amount of MDA formed was measured spectrophotometrically at $532 \mathrm{~nm}$.

\section{Glutathione Reductase (GR)}

GR activity of liver homogenate was determined by measuring the reduction of GSSG in the presence of NADPH as described by Mize and Langdon [16] with slight modification. Briefly, this assay measures the rate of $\mathrm{NADPH}$ oxidation to $\mathrm{NADP}+$, which is accompanied 
Citation: Syama S, Reshma SC, Leji B, Anju M, Sreekanth PJ, et al. (2014) Toxicity Evaluation of Dextran Coated Ferrite Nanomaterials After Acute Oral Exposure to Wistar Rats. J Allergy Ther 5: 166. doi:10.4172/2155-6121.1000166

by a decrease in absorbance at $340 \mathrm{~nm}$, which can be monitored spectrophotometrically. Thus, one GR unit is defined as the reduction of one $\mu \mathrm{M}$ of GSSG per minute at $25^{\circ} \mathrm{C}$ and $\mathrm{pH} 7.6$.

\section{Reduced Glutathione (GSH)}

The concentration of reduced GSH was determined by the method of Moron et al. [17], with slight modifications in which DTNB (5, 5'-dithiobis-(2-nitrobenzoic acid), reacts with GSH to form a spectrophotometrically detectable product that absorbs at wavelength of $412 \mathrm{~nm}$. The change in absorbance at $412 \mathrm{~nm}$ is directly proportional to the GSH concentration in the reaction mixture. The amount of GSH present in the sample was expressed as $\mathrm{nmol} / \mathrm{mg}$ protein.

\section{Glutathione Peroxidase (GPx)}

Activity of GPx in liver homogenate was assayed by the method described by Rotruck et al. [18]. This enzyme catalyzes the formation of glutathione disulfide (GSSG) from GSH. The remaining GSH after the enzyme catalyzed reaction complexed with DTNB, which absorbs at maximum wavelength of $412 \mathrm{~nm}$. Enzyme activity was expressed as $\mu \mathrm{g}$ of GSH consumed/min/mg protein.

\section{Superoxide Dismutase Assay (SOD)}

Activity of superoxide dismutase, an enzyme that dismutates the superoxide anion radical was assessed as explained by Marklund [19]. Under higher $\mathrm{pH}$, Pyrogallol auto oxidizes in aqueous solution. The method is based on the inhibition of superoxide dismutase (SOD) on pyrogallol auto oxidation which was observed by decrease in absorbance at $420 \mathrm{~nm}$.

All measurements were carried out using UV Spectrophotometer-1601, Shimadzu, Japan.

\section{Statistical Analysis}

All values are expressed as mean \pm SD. Statistical differences between the control and experimental values were compared by Student's ' $t$ ' test. For all comparisons, $p<0.05$ was considered significant.

\section{Results}

\section{Synthesis and characterization of DFNM}

Ferrite nanoparticles were prepared by the standard coprecipitation method and coated with dextran to yield dextran coated ferrite nanoparticles. The Transmission Electron Microscopic (TEM) image indicates a very uniform size distribution of DFNM particles and was found to be less than $25 \mathrm{~nm}$ (Figure 1).

\section{Acute toxicity}

All the animals exposed to DFNM were observed periodically during the first 24 hours, and thereafter daily for 14 days. Appearance of skin, fur, eyes, respiratory, autonomic and central nervous system were monitored during these days. No changes on skin, fur, eyes, respiratory, autonomic and central nervous system were observed during these days. None of the animals showed any abnormal behavior like tremors, convulsion, salivation, diarrhoea, lethargy, sleep, coma or death. There was no loss in body weight. At the end of observation period, all animals were sacrificed and gross examination of all the organs appeared normal.

\section{Haematological and biochemical parameters}

At the end of experimental period, blood was subjected for the

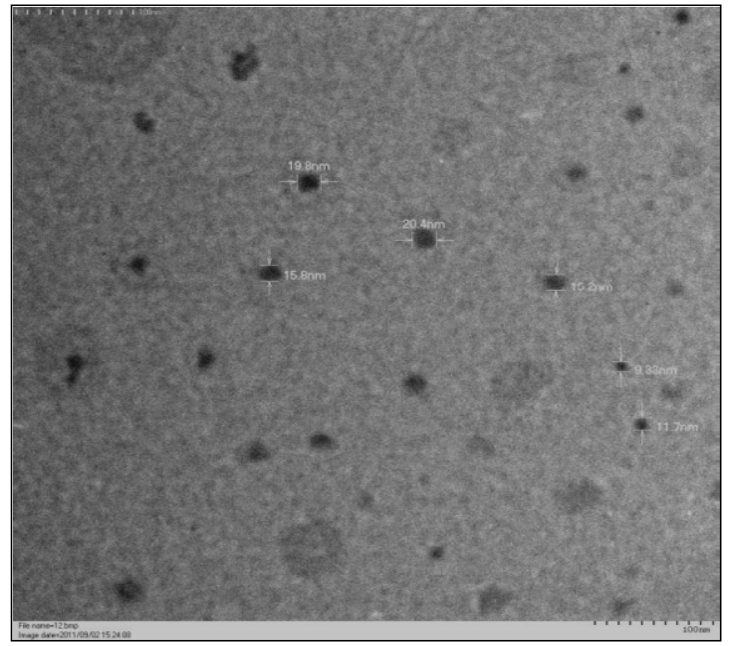

Figure 1: TEM image of DFNM (X30K).

\begin{tabular}{|l|l|l|l|}
\hline Parameters & \multicolumn{3}{|c|}{ Mean \pm SD } \\
\cline { 2 - 4 } & Control & $\begin{array}{l}\text { 300 } \mathbf{~ m g / k g ~ b o d y ~} \\
\text { weight }\end{array}$ & $\begin{array}{l}\text { 2000mg/kg body } \\
\text { weight }\end{array}$ \\
\hline WBC $\left(10^{3} / \mathrm{mm}^{3}\right)$ & $6.93 \pm 1.46$ & $7.17 \pm 1.62$ & $6.83 \pm 1.01$ \\
\hline RBC $\left(10^{6} / \mathrm{mm}^{3}\right)$ & $6.71 \pm 0.18$ & $6.80 \pm 0.48$ & $6.54 \pm 0.41$ \\
\hline HGB $(\mathrm{g} / \mathrm{dL})$ & $15.27 \pm 0.31$ & $14.83 \pm 0.81$ & $14.9 \pm 0.95$ \\
\hline HCT $(\%)$ & $36.6 \pm 0.49$ & $35.30 \pm 2.44$ & $35.53 \pm 1.62$ \\
\hline MCV & $54 \pm 1.00$ & $53.67 \pm 1.53$ & $54.33 \pm 1.15$ \\
\hline MCH & $22.4 \pm 0.35$ & $22.77 \pm 0.93$ & $22.8 \pm 0.7$ \\
\hline MCHC & $41.13 \pm 0.35$ & $42.4 \pm 0.66$ & $41.93 \pm 1.00$ \\
\hline
\end{tabular}

(Student's ' $t$ ' test. For all comparisons $p<0.05$ was considered significant, $\mathrm{n}=3$

Table 1: Haematological parameters of DFNM administered animals.

\begin{tabular}{|c|c|c|c|}
\hline \multirow[t]{2}{*}{ Biochemical Parameters } & \multicolumn{3}{|c|}{ Mean \pm SD } \\
\hline & Control & $\begin{array}{l}300 \mathrm{mg} / \mathrm{kg} \text { body } \\
\text { weight }\end{array}$ & $\begin{array}{l}2000 \mathrm{mg} / \mathrm{kg} \\
\text { body weight }\end{array}$ \\
\hline Total Protein (g/dL) & $7.23 \pm 0.21$ & $7.7 \pm 0.2^{*}$ & $8.23 \pm 0.87$ \\
\hline Creatinine (mg/dL) & $0.89 \pm 0.02$ & $0.98 \pm 0.11$ & $0.79 \pm 0.09$ \\
\hline Urea $(\mathrm{mg} / \mathrm{dL})$ & $30.77 \pm 2.04$ & $34.6 \pm 2.36$ & $33.53 \pm 3.88$ \\
\hline SGPT (U/L) & $76.6 \pm 10.86$ & $89.95 \pm 18.31$ & $54.75 \pm 2.89$ \\
\hline SGOT (U/L) & $142.2 \pm 7.3$ & $129.1 \pm 0.14$ & $106.63 \pm 9.15^{\star}$ \\
\hline Alkaline Phosphatase (U/L) & $135.1 \pm 2.08$ & $177 \pm 16.97$ & $165 \pm 4.24^{*}$ \\
\hline Glucose (mg/dL) & $101.05 \pm 0.49$ & $87.1 \pm 2.82$ & $117.75 \pm 2.05^{\star}$ \\
\hline Cholesterol (mg/dL) & $98 \pm 1.00$ & $78.33 \pm 10.16$ & $87.67 \pm 6.81$ \\
\hline Bilirubin Total (mg/dL) & $0.08 \pm 0.01$ & $0.36 \pm 0.25$ & $0.22 \pm 0.25$ \\
\hline Albumin (BCG) (g/dL) & $4.46 \pm 0.59$ & $4.3 \pm 0.1$ & $4.13 \pm 0.15$ \\
\hline Phosphorus (mg/dL) & $5.63 \pm 0.14$ & $7.6 \pm 3.32$ & $6.72 \pm 1.35$ \\
\hline Chlorides (mEq/L) & $97.13 \pm 2.35$ & $103.1 \pm 0.56^{*}$ & $101.3 \pm 0.82^{*}$ \\
\hline GGT (U/L) & $1.47 \pm 0.99$ & $1.77 \pm 1.59$ & $2.33 \pm 1.30$ \\
\hline
\end{tabular}

(Student's ' $t$ ' test. For all comparisons, $p<0.05$ was considered significant), * $(p$ value $<0.05, \mathrm{n}=3$ )

Table 2: Biochemical parameters of DFNM administered animals.

analysis of haematological (WBC, RBC, Haemoglobin, hematocrit, $\mathrm{MCV}, \mathrm{MCH}, \mathrm{MCHC}$ ) and biochemical (glucose, cholesterol, total bilirubin, albumin, chloride, total protein, creatinine, urea, SGPT, SGOT, alkaline phosphatise, GGT) parameters. Table 1 indicates the haematological parameters of DFNM exposed groups and slight fluctuation was seen when compared to control values, but the changes were not statically significant, when compared to control values.

The report of biochemical parameters were given in the Table 2. It 
was noted that, there was a slight changes in some of the biochemical values (statistically significant, $p$ value $<0.05$ ) between control and treated groups.

\section{Lipid peroxidation}

An increase in lipid peroxides level in liver tissue homogenates of treated animals was measured (Figure 2). The mean value of LPO was found to be $4.61 \pm 0.71(300 \mathrm{mg} / \mathrm{kg}), 4.82 \pm 0.07(2000 \mathrm{mg} / \mathrm{kg})$ whereaks in control group it shows only $3.42 \pm 017$.

\section{Activity of GR}

The activity of GR increased in a concentration dependent manner that was evident from the Figure 3. The GR activity increased in 2000 $\mathrm{mg} / \mathrm{kg}$ exposed group $(0.526 \pm 0.03)$ with respect to control $(0.286 \pm$ $0.02)$. The mean value observed in $300 \mathrm{mg} / \mathrm{kg}$ treated group was 0.456 \pm 0.07 . Both are statistically significant $(p$ value $<0.05)$.

\section{Level of GSH}

No change was measured in GSH concentration in the group treated with the low dose $(300 \mathrm{mg} / \mathrm{kg})$ of DFNM when compared to control non treated one, whereas a slight increase in GSH level was obtained in high dose of DFNM $(2000 \mathrm{mg} / \mathrm{kg})$ treated groups that was found to be insignificant on comparison.

The level of reduced glutathione remains the same in the $300 \mathrm{mg} /$ $\mathrm{kg}$ exposed $(1.10 \pm 0.10)$ and in control $(1.10 \pm 0.02)$ groups. The

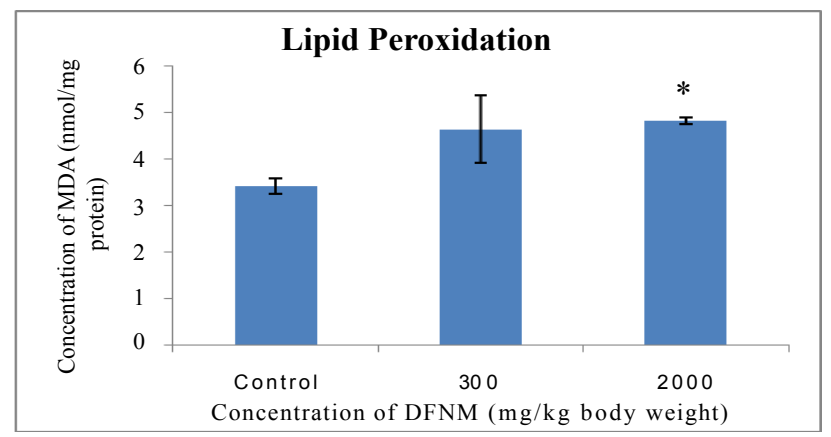

Figure 2: Lipid peroxide level in tissue homogenates of DFNM treated rats ( ${ }^{*} \mathrm{p}$ value $<0.05, \mathrm{n}=4$ ).

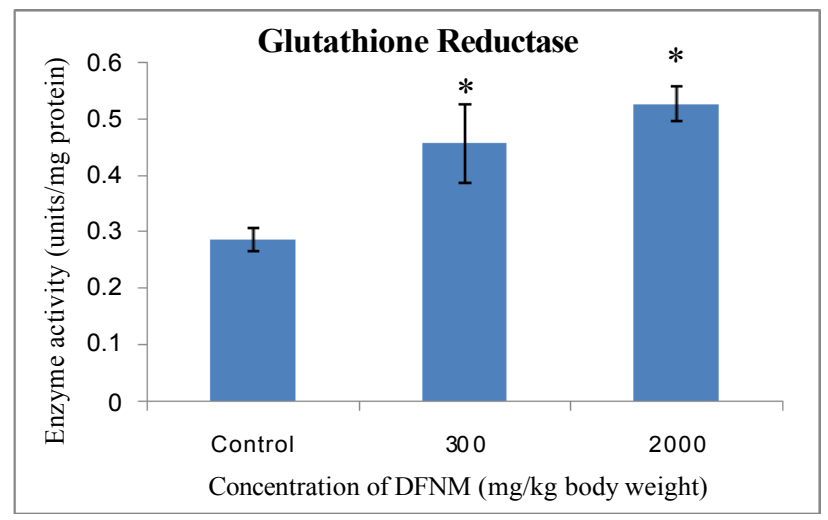

Figure 3: Glutathione Reductase activity in tissue homogenates of DFNM treated rats ( ${ }^{*} p$ value $\left.<0.05, n=4\right)$.

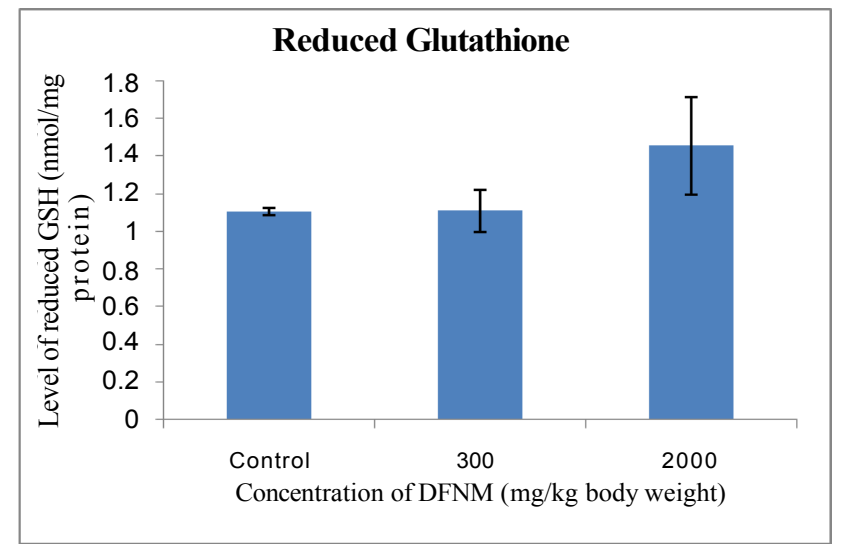

Figure 4: Reduced Glutathione activity in tissue homogenates of DFNM treated rats. $n=4$.

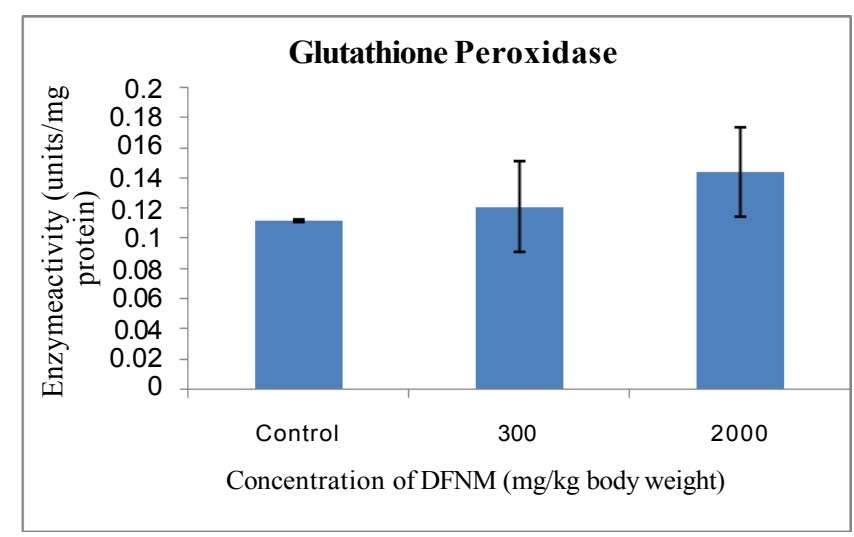

Figure 5: Glutathione peroxidase activity in tissue homogenates of DFNM treated rats. $n=4$.

concentration was slightly increased in $2000 \mathrm{mg} / \mathrm{kg}$ treated group and was observed to be $1.42 \pm 0.25$ (Figure 4).

\section{Activity of GPx}

The GPx activity remains the same in both the treated as well as control group (Figure 5). The mean values were $(0.121 \pm 0.03),(0.144$ $\pm 0.03)$ and $(0.112 \pm 0.001)$ for $300 \mathrm{mg} / \mathrm{kg}, 2000 \mathrm{mg} / \mathrm{kg}$ treated groups and the control respectively.

\section{Activity of SOD}

SOD also showed dose dependent increase in activity that was clear from the Figure 6 . The mean value for the $300 \mathrm{mg} / \mathrm{kg}$ exposed group was $0.109 \pm 0.008$ and for the $2000 \mathrm{mg} / \mathrm{kg}$ exposed group was 0.119 \pm 0.025 . Both the values were higher than the control $(0.084 \pm 0.002)$ values.

\section{Discussion}

The safety and toxicity of nanomaterials are of growing concern despite their significant scientific interest and promising potential in many applications. Their biological activity and biokinetics are dependent on many parameters, such as size, shape, chemistry, charge, surface modifications etc. Health effects of nanomaterials are attracting considerably and increasing concern of the public and government worldwide. So far, most of the nanotoxicological research 


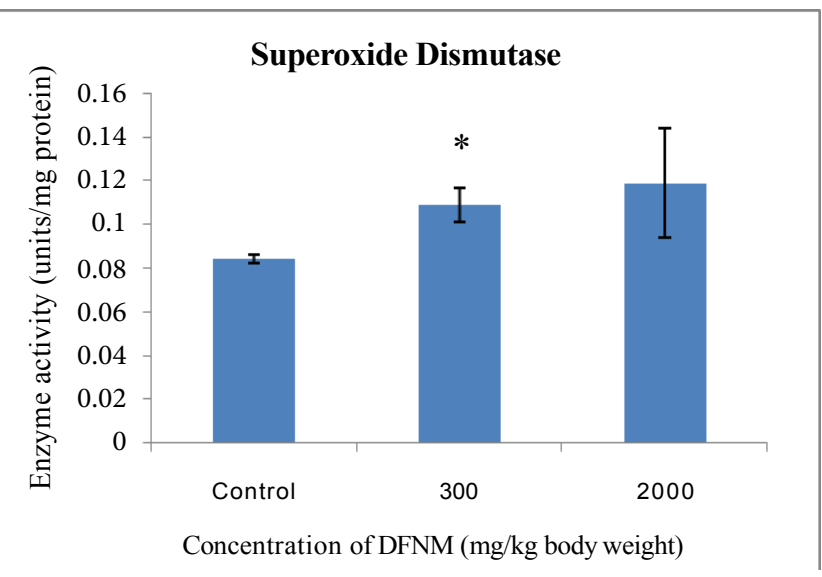

Figure 6: Superoxide dismutase activity in tissue homogenates of DFNM treated rats. ( ${ }^{*} p$ value $\left.<0.05, \mathrm{n}=4\right)$.

focused on respiratory tract exposures for assessing the health effects of nanoparticles. Other exposure routes, e.g., gastrointestinal tract also need to be considered as potential portals of entry. The present study focused on the acute oral toxicity of DFNM and its effects on the cellular level. The size of the nanoparticles influences its property and their interaction with the biological system. The result of the TEM study indicates that the synthesized DFNM was an authentic particle and has a size less than $25 \mathrm{~nm}$.

In this study the DFNM was suspended in aqua guard water and was loaded in a syringe after thorough agitation. A single administration of this suspension containing DFNM was given to rats using a gastric needle. All the animals were observed for 14 days and found that none of the animals showed any adverse effects or toxicity or death. The gross examination report showed that there was no abnormality detected in any of the organs.

It was reported [20] that the toxicity of nanoparticles depends on their properties like size, shape, surface chemistry etc., the route of exposure of nanoparticles plays a key role in determining their biodistribution and the rate of clearance from the body. Most of the nanoparticles injected via oral route showed increased accumulation in liver, spleen and kidney. Acute toxic study of copper and zinc nanoparticles on mice showed color change and atrophy in mice. The mice treated with nano zinc suspensions suffered from lethargy, nausea, vomiting and diarrhea [21]. Dextran coated nanoparticles are widely used in imaging by magnetic resonance (MRI), optical and positron emission tomography (PET) etc., These nanoparticles offer extended vascular retention time and are non toxic, biodegradable [22].

The rationale of the present study is to investigate the biological response of DFNM when orally administered to rats and to gain insights into its action. Acute oral toxicity in Wistar rats showed that the general physical conditions of the experimental animals were normal during the experimental period. The results indicated that there was no alternation in the haematological values. It was also noted that there was no major alternations observed in the biochemical parameters, when different concentrations of DFNM (300 and 2000 $\mathrm{mg} / \mathrm{kg}$ ) exposed to rats.

Oxidative stress, one of the leading mechanisms of nanoparticles toxicity often results in increase in reactive oxygen species inside the cell. ROS encompasses variety of partially reduced oxygen metabolites like superoxide anions, hydrogen peroxides and hydroxyl radicals [23].
ROS occurs as a normal metabolic end product. The major site of ROS production is mitochondria as a result of respiratory chain. Interaction of ROS with cell components results in their structural modifications [24].

Lipids are the major site of ROS modification resulting in peroxides formation. Lipid peroxidation, is a chain reaction that propagates by peroxy radicals and prolongs till unsaturated lipid molecules are available [25]. In the present study, there was a slight increase in lipid peroxidation observed in the treated group when compared to control, but level of peroxides formation remain the same (on both in 300 and $2000 \mathrm{mg} / \mathrm{kg}$ exposed group) suggesting that DFNM seems to induce peroxide formation on initial stage, reaching a saturation level (plateau) after that it does not elicit any further increase. Thus a cell possesses several mechanisms to overcome the negative consequences of lipid peroxidation above a particular level.

There are various antioxidant enzymes present in a cell, which tracks on the level of ROS formed. Oxidative stress occurs when a cell fails to establish a correlation between the levels of ROS generated and the activity of antioxidant defense system. Among the various antioxidants, reduced glutathione exhibit a prime role by acting as a scavenger of ROS. The thiol group of GSH plays a critical role in antioxidant defense. GSH act as a substrate for glutathione peroxidase forming glutathione disulfide (GSSG). GSSG formed further reduced to GSH by glutathione reductase in a NADPH dependent manner [26]. Though there was an increase in activity of GPx, an indication of increase in ROS production, the cell tries to defeat the effect of ROS by upholding the level of reduced glutathione. The increased level of GSH, was established by the activity of glutathione reductase that reduce two molecules of GSH for one molecule of GSSG formed.

Super oxide dismutase is the first line of antioxidant defense enzyme that acts against the free oxygen radical. $\mathrm{Cu}-\mathrm{Zn}$ SOD is an enzyme widely distributed in eukaryotic cells localized in the cytoplasm, while Mn-SOD, can be found in prokaryotic cells and eukaryotic mitochondria. The end product of dismutation $\mathrm{H}_{2} \mathrm{O}_{2}$ is catalyzed by other enzymes like catalase and glutathione peroxidase [27]. The increase in SOD activity observed signifies that the cell tries to rescue from the effect of superoxide radical generated. Difference in the above antioxidant parameters was found to be insignificant, implies that the synthesized DFNM does not induce oxidative stress and the cell can able to manage the slight changes initiated in response to DFNM introduction. Since there was no adverse symptoms/toxicity or death at the dose of $2000 \mathrm{mg} / \mathrm{kg}$ body weight, the DFNM is classified as an unclassified compound (non toxic) as per Globally Harmonized System for Classification (Category 5) for chemical substances and mixtures (OECD 423).

\section{Conclusion}

The results of the acute toxicity study demonstrated that the synthesized DFNM has a particle size less than $25 \mathrm{~nm}$ and is considered as an unclassified compound (showing no specific organ toxicity seen at the proposed concentration tested) as per Globally Harmonized System for Classification for chemical substances and mixtures. There was no significant fluctuation in the level of haematological, biochemical, antioxidant defense mechanism and lipid peroxidation. Hence, it can be concluded that the synthesized DFNM was non-toxic at $2000 \mathrm{mg} / \mathrm{kg}$ body weight and has no molecular level toxicity when exposed orally in rats, promising their use for biomedical applications.

\section{Acknowledgment}

Authors are thankful to the Director and Head, Biomedical Technology Wing, 
Citation: Syama S, Reshma SC, Leji B, Anju M, Sreekanth PJ, et al. (2014) Toxicity Evaluation of Dextran Coated Ferrite Nanomaterials After Acute Oral Exposure to Wistar Rats. J Allergy Ther 5: 166. doi:10.4172/2155-6121.1000166

Page 6 of 6

Sree Chitra Tirunal Institute for Medical Sciences and Technology for providing the facilities to carry out the work. We also acknowledge the technical assistance of Mr. Shaji S, Mr. Harikumar G. The work was financially supported by the Nanomission Department of Science and Technology (Govt. of India), New Delhi, (Grant No. SR/ NM/NS-90/2008).

\section{References}

1. Corot C, Robert P, Idée JM, Port M (2006) Recent advances in iron oxide nanocrystal technology for medical imaging. Adv Drug Deliv Rev 58: 1471 1504.

2. Ito A, Kamihira $M(2011)$ Tissue engineering using magnetite nanoparticles. Prog Mol Biol Transl Sci 104: 355-395

3. Kim DH, Nikles DE, Johnson DT, Brazel CS (2008) Heat generation of aqueously dispersed $\mathrm{CoFe} 2 \mathrm{O} 4$ nanoparticles as heating agents for magnetically activated drug delivery and hyperthermia. J Magn Magn Mater 320: 2390-2396.

4. Chomoucka J, Drbohlavova J, Huska D, Adam V, Kizek R, et al. (2010) Magnetic nanoparticles and targeted drug delivering. Pharmacol Res 62: 144149

5. Di Corato R, Bigall NC, Ragusa A, Dorfs D, Genovese A, et al. (2011) Multifunctional nanobeads based on quantum dots and magnetic nanoparticles: synthesis and cancer cell targeting and sorting. ACS Nano 5: 1109-1121.

6. Kumar A, Sahoo B, Montpetit A, Behera S, Lockey RF, et al. (2007) Development of hyaluronic acid-Fe2O3 hybrid magnetic nanoparticles for targeted delivery of peptides. Nanomedicine 3: 132-137.

7. Thiesen B, Jordan A (2008) Clinical applications of magnetic nanoparticles for hyperthermia. Int J Hyperthermia 24: 467-474.

8. Kim JS, Yoon TJ, Yu KN, Noh MS, Woo M, et al. (2006) Cellular uptake of magnetic nanoparticle is mediated through energy-dependent endocytosis in A549 cells. J Vet Sci 7: 321-326.

9. Taylor MS, Daniels AU, Andriano KP, Heller J (1994) Six bioabsorbable polymers: in vitro acute toxicity of accumulated degradation products. $\mathrm{J}$ Appl Biomater 5: 151-157.

10. AshaRani PV, Low KahMun G, Hande MP, Valiyaveettil S (2009) Cytotoxicity and genotoxicity of silver nanoparticles in human cells. ACS Nano 3: 279-290.

11. Sutton A, Harrison GE, Carr TE, Barltrop D (1971) Reduction in the absorption of dietary strontium in children by an alginate derivative. Int J Radiat Biol Relat Stud Phys Chem Med 19: 79-85.

12. Ansar EB, Ajesh M, Yokogawa Y, Wunderlich W, Varma HK (2012) Synthesis and characterization of iron oxide embedded hydroxyapatite bioceramics. J Am Ceram Soc 95: 2695-2699.
13. OECD Guidelines 423 (2001) Acute oral toxicity-Acute Toxic Class Method Adopted.

14. Lowry OH, Rosebrough NJ, Farr AL, Randall RJ (1951) Protein measurement with the Folin phenol reagent. J Biol Chem 193: 265-275.

15. Ohkawa HN, Ohishi N, Yagi K (1979) Assay for lipid peroxides in animal tissues by thiobarbituric acid reaction. Anal Biochem 95: 351-358.

16. Mize CE, Langdon RG (1962) Hepatic glutathione reductase. I. Purification and general kinetic properties. J Biol Chem 237: 1589-1595.

17. Moron MS, Depierre JW, Mannervik B (1979) Levels of glutathione, glutathione reductase and glutathione S-transferase activities in rat lung and liver. Biochim Biophys Acta 582: 67-78.

18. Rotruck JT, Pope AL, Ganther HE, Swanson AB, Hafeman DG, et al. (1973) Selenium: biochemical role as a component of glutathione peroxidase. Science 179: 588-590.

19. Marklund S, Marklund G (1974) Involvement of the superoxide anion radical in the autoxidation of pyrogallol and a convenient assay for superoxide dismutase. Eur J Biochem 47: 469-474.

20. Chen Z, Meng H, Xing G, Chen C, Zhao Y, et al. (2006) Acute toxicological effects of copper nanoparticles in vivo. Toxicol Lett 163: 109-120.

21. Wang B, Feng WY, Wang TC, Jia G, Wang M, et al. (2006) Acute toxicity of nano- and micro-scale zinc powder in healthy adult mice. Toxicol Lett 161 115-123.

22. Tassa C, Shaw SY, Weissleder R (2011) Dextran-coated iron oxide nanoparticles: a versatile platform for targeted molecular imaging, molecular diagnostics, and therapy. Acc Chem Res 44: 842-852.

23. Martindale JL, Holbrook NJ (2002) Cellular response to oxidative stress signaling for suicide and survival. J Cell Physiol 192: 1-15.

24. Shukla RK, Kumar A, Gurbani D, Pandey AK, Singh S, et al. (2013) TiO(2) nanoparticles induce oxidative DNA damage and apoptosis in human liver cells. Nanotoxicology 7: 48-60.

25. Kumar A, Pandey AK, Singh SS, Shanker R, Dhawan A (2011) Engineered ZnO and $\mathrm{TiO}(2)$ nanoparticles induce oxidative stress and DNA damage leading to reduced viability of Escherichia coli. Free Radic Biol Med 51: 1872-1881.

26. Dickinson DA, Forman HJ (2002) Cellular glutathione and thiols metabolism Biochem Pharmacol 64: 1019-1026.

27. Ron Kohen, Abraham Nyska (2002) Invited Review: Oxidation of Biological Systems: Oxidative Stress Phenomena, Antioxidants, Redox Reactions, and Methods for Their Quantification. Toxicol Pathol 30: 620-650. 